\title{
Seasonal Distribution of Fungi in Soil Found in Two Hospitals in Bandar Abbas, Iran
}

\author{
Elham Shahbazy ${ }^{1}$, Negin Azizi ${ }^{1}$, Parivash Davoodian², Khojasteh Sharifi_Sarasiabi ${ }^{3}$, Afsaneh Karmostaji ${ }^{4}$
}

${ }^{1}$ B.Sc. of Laboratory Sciences, Student Research Committee, Hormozgan University of Medical Sciences, Bandar Abbas, Iran

${ }^{2}$ M.D., Infectious Diseases Specialist. Assistant Professor, Infectious and Tropical Diseases Research Center, Hormozgan University of Medical Sciences, Bandar Abbas, Iran

${ }^{3}$ Ph.D. of Parasitology, Assistant Professor, Infectious and Tropical Diseases Research Center, Hormozgan University of Medical Sciences, Bandar Abbas, Iran

${ }^{4} \mathrm{Ph} . \mathrm{D}$. of Bacteriology, Assistant Professor, Infectious and Tropical Diseases Research Center, Hormozgan University of Medical Sciences, Bandar Abbas, Iran

\section{Type of article: Original}

\begin{abstract}
Introduction: Fungal contamination in hospitals has been a major health concern, especially in immunosuppressed patients. Construction programs increase the risk of fungal contaminations in hospitals. This study aimed to monitor and compare fungal contamination in two hospitals in Bandar Abbas, Iran, one of which was undergoing construction. Furthermore, the study determined the seasonal variations in the prevalence of fungi identified in the two hospitals.

Methods: This study was conducted during April-December 2014 on 146 soil samples collected from the Shahid Mohammadi Hospital that was under construction and the Shariati Hospital that was not involved in any construction program. The soil samples were collected in the morning from the dust on the ground. Statistical analysis was performed using the chi-squared test.

Results: Among the fungal cultures, $83.56 \%$ were found to be positive. We identified 122 fungal isolates, representing 16 genera, 13 of the genera were isolated from Shahid Mohammadi Hospital and 14 were isolated from Shariati Hospital. Aspergillus was the dominant fungus in both hospitals. In Shariati Hospital, 100\% of Aspergiluss niger were isolated in the summer. In the spring, Mocur was dominant in both hospitals, and, in the winter, Rhizopus spp. was the dominant fungus in Shahid Mohammadi Hospital (55.5\%); however, this fungus was dominant in spring in Shariati Hospital (66.7\%). In Shariati Hospital, Scopulariopsis, Drechslera, Penicillium spp., and Yeasts were present only in the fall, whereas yeast was the dominant fungus in summer $(100 \%)$ in Shahid Mohammadi Hospital. There were not significant differences between two hospitals, with the exception of Fusarium spp., which was more frequent in Shariati Hospital, where no renovation was taking place $(\mathrm{p}=0.008)$.

Conclusion: Our results indicated that specific ecological niches existed in the two general hospitals in Bandar Abbas. Special attention should be paid to environmental control programs. It is recommended that soil exposure be considered in patients' histories in addition to the current focus on infections related to food and water.

Keywords: fungi, soil microbiology, hospital, seasons
\end{abstract}

\section{Introduction}

It seems that we are faced with the threat of increased incidence of invasive fungal infections. A study conducted in 2007 involving 1265 Intensive Care Units in 75 countries around the world showed that $19 \%$ of pathogens in patients admitted to the Intensive Care Unit (ICU) were fungi (1). The prevalence of fungal infections in ICUs in

\section{Corresponding author:}

Assistant Professor Dr. Afsaneh Karmostaji, Infectious and Tropical Diseases Research Center, Hormozgan University of Medical Sciences, Bandar Abbas, Iran.

Tel: +98.7633666367, Fax:+98.7633670724, Email: Afsanehkk@yahoo.com

Received: July 25, 2015, Accepted: October 01, 2015, Published: November 2015

iThenticate screening: August 07, 2015, English editing: September 15, 2015, Quality control: November 05, 2015

(C) 2015 The Authors. This is an open access article under the terms of the Creative Commons Attribution-NonCommercialNoDerivs License, which permits use and distribution in any medium, provided the original work is properly cited, the use is non-commercial and no modifications or adaptations are made. 
Iran in 2011 was $1.9 \%$ with a mortality rate of $58.8 \%$ (2). Since construction at the site of the hospital was causing fungal spores to be dispersed throughout the environment, the overall construction-related mortality was reported to be as high as 50\% in 2015 (3). Another study conducted in 2015 indicated that invasive fungal infections were responsible for the deaths of 1.4 million people annually (4). Immunosuppressed patients, such as patients with HIV infections are at high risk of fungal contamination, because fungal spores can be inhaled and cause local or invasive infections. The main fungal genera responsible for these infections are Aspergillus spp., Fusarium spp., Scedosporium spp., and Mucorales (5). Penicillium marneffei was the agent for fatal systemic mycosis in patients infected with HIV in Southeast Asia, especially during the rainy season (6). Furthermore, a variety of nondimorphic, soil-related yeasts and molds, including Rhizopus and Mucor, can cause significant local or systemic infections in people. The sources of fungal spores are soil, decaying vegetation, and dust (7). In hospital environments, soil and dust are transmitted through ventilators and air conditioning systems, and decaying materials, food, and water are possible sources of fungal spores that can cause nosocomial infections. Particularly, construction work in and around hospitals increases the risk of nosocomial infections caused by airborne fungi (5). With respect to the seasonal variations of fungi, some European studies have reported seasonal distributions of Cladosporium spp., Alternaria spp., and Aspergillus spp. in outdoor air (8). Invasive fungal infections, depending on their types and the risk factors of patients, can result in a fivefold increase in death, cause extended hospitalization up to 19.2 days, and increase costs to between 55.400\$ (9) to $€ 9.36-€ 13.24 \$$ (10). At the time of this study, Shahid Mohammadi Hospital in Bandar Abbas, Iran, was involved in a large renovation program that included the construction of buildings. Our aim was to monitor fungal contamination in the Hospital during the construction period and compare it with another hospital that was not involved in any construction program during the same period. Furthermore, we evaluated the seasonal variations of the main fungi identified in these hospitals.

\section{Material and Methods}

\subsection{Research design and setting}

This study was conducted during April-December 2014 using hospital soil samples that were collected from two hospitals in Bandar Abbas, Iran. Bandar Abbas is a port city, is the capital of Hormozgan Province, and has approximately 500,000 inhabitants (11). The average temperature range in winter is $17-25^{\circ} \mathrm{C}$, and it is $35-40{ }^{\circ} \mathrm{C}$ in the summer, with a relative humidity of about $85 \%$. Shahid Mohammadi Hospital is a 400-bed University Hospital in Bandar Abbas, and, at the time of this study, the Hospital was involved in a large renovation program, including the construction in hospital. The other hospital in Bandar Abbas that was involved in this study was the Shariati Hospital, and it had no construction taking place at the time of this study. We collected 146 soil samples from 54 locations at the two Hospitals, with 53 samples from the site of the Shariati Hospital and 93 samples from the site of the Shahid Mohammadi Hospital. The samples were taken randomly at 12-m intervals at each site (12). The soil samples were taken from a depth of 5 to $8 \mathrm{~cm}$ at each location.

\subsection{Data collection and methods}

Soil samples consisting of 3-5 grams, each were collected in the morning from the dust that had settled down during the night. Twenty-five samples were taken in the winter at temperatures of $17-25^{\circ} \mathrm{C}$, and 23 samples were collected in the summer at temperatures of $32-37^{\circ} \mathrm{C}$. Twenty samples were collected in the spring, and 25 samples were collected in the fall. Three-to-five grams of each soil sample were taken from the air conditioning ducts, corridors, and garden soil at a depth of 5-8 $\mathrm{cm}$. The samples were removed using a sterile wooden spatula, and they were placed into sterile petri dishes. Each soil sample was given a code that contained related information, such as temperature, moisture content, $\mathrm{pH}$, type of vegetation, redox potential, location in the shade or sun exposure and transferred to the Mycology Laboratory of the School of Medicine at Hormozgan University of Medical Sciences. The soil samples were dried in air at $25^{\circ} \mathrm{C}$ for seven days. We added 3-to-5 grams of the soil samples to test tubes that contained $25 \mathrm{ml}$ of sterile physiologic saline $(0.9 \% \mathrm{NaCl})$ at $25{ }^{\circ} \mathrm{C}$, stirred the mixture for 5 min, and waited 25 min for the soil to settle. In order to inhibit the growth of bacteria, $8 \mathrm{ml}$ of the supernatant were added to another sterile test tube that contained $2 \mathrm{ml}$ of streptomycin and penicillin antibiotic solutions $(2 \mathrm{mg} / \mathrm{L})$, mixed the contents, and incubated them for $30 \mathrm{~min}$. This solution was mixed again, and $0.5 \mathrm{ml}$ of it was transferred to a Sabouraud's dextrose agar medium (BioMeriéux, Marcy-1, Etoil, France) that contained $0.5 \mathrm{~g} / \mathrm{L}$ of cycloheximide, and we incubated at the mixture at $25^{\circ} \mathrm{C}$ for two weeks (13). Statistical analysis was performed using the chi-squared test.

\section{Results}

Among the 146 soil samples in the study, 83.56\% of them were positive for fungal cultures. Altogether, 122 fungi isolates were diagnosed, representing 16 genera. Thirteen genera were isolated from the samples taken at Shahid 
Mohammadi Hospital and 14 genera were isolated from samples taken at Shariati Hospital. Eleven genera were found at both of the hospitals (Table 1).

Table 1. Frequency (\%) of fungi isolated from the two hospitals

\begin{tabular}{|l|l|l|l|l|}
\hline Isolate & $\mathrm{HA} ; \mathrm{n}^{1}(\%)$ & $\mathrm{HB} ; \mathrm{n}^{2}(\%)$ & Total; $\mathrm{n}^{3}(\%)$ & $\mathrm{p}$-value \\
\hline Aspergillus spp. & $10(24.39)$ & $20(24.47)$ & $30(24.59)$ & 0.98 \\
\hline Aspergillus niger & $3(7.32)$ & $15(18.52)$ & $18(14.75)$ & 0.069 \\
\hline Mucor spp. & $5(12.19)$ & $9(11.11)$ & $14(11.47)$ & 0.81 \\
\hline Rhizopus spp & $3(7.32)$ & $9(11.11)$ & $12(9.83)$ & 0.35 \\
\hline Penicillium spp & $2(4.88)$ & $8(9.87)$ & $10(8.19)$ & 0.17 \\
\hline Alternaria spp. & $3(7.32)$ & $4(4.94)$ & $7(5.74)$ & 0.48 \\
\hline Epicoccum & $4(9.76)$ & $3(3.70)$ & $7(5.74)$ & 0.08 \\
\hline Fusarium spp. & $5(12.19)$ & $2(2.47)$ & $7(5.74)$ & 0.008 \\
\hline Yeasts & $1(2.44)$ & $3(3.70)$ & $4(3.28)$ & 0.60 \\
\hline Mycelia Sterilia & 0 & $3(3.70)$ & $3(2.46)$ & 0.05 \\
\hline Drechslera spp & $1(2.44)$ & $2(2.47)$ & $3(2.46)$ & 0.98 \\
\hline Psylomyces & $1(2.44)$ & $2(2.47)$ & $3(2.46)$ & 0.98 \\
\hline Absidia & 0 & $1(1.23)$ & $1(0.82)$ & 0.26 \\
\hline Scopulariopsis & $1(2.44)$ & 0 & $1(0.82)$ & 0.11 \\
\hline Phoma & $1(2.44)$ & 0 & $1(0.82)$ & 0.11 \\
\hline Ascocarpe & $1(2.44)$ & 0 & $1(0.82)$ & 0.11 \\
\hline
\end{tabular}

1: From total of 81; 2: From total of 41, 3: from total of 122; HA: Shariati Hospital; HB: Shahid Mohammadi Hospital

Table 2. Incidence and seasonal variation of different types of fungi isolated from the soil of Shariati Hospital and Shahid Mohammadi Hospital in Bandar Abbas

\begin{tabular}{|c|c|c|c|c|c|c|c|c|c|c|}
\hline \multirow{2}{*}{$\begin{array}{l}\text { Fungal } \\
\text { Species } \\
\text { Isolated }\end{array}$} & \multicolumn{2}{|l|}{ Winter } & \multicolumn{2}{|l|}{ Spring } & \multicolumn{2}{|c|}{ Summer } & \multicolumn{2}{|l|}{ Fall } & \multicolumn{2}{|l|}{ Total } \\
\hline & $\begin{array}{l}\text { HA } \\
\text { n (\%) }\end{array}$ & $\begin{array}{l}\text { HB } \\
\text { n (\%) }\end{array}$ & $\begin{array}{l}\text { HA } \\
\text { n (\%) }\end{array}$ & $\begin{array}{l}\text { HB } \\
\text { n (\%) }\end{array}$ & $\begin{array}{l}\mathrm{HA} \\
\mathrm{n}(\%)\end{array}$ & $\begin{array}{l}\text { HB } \\
\text { n (\%) }\end{array}$ & $\begin{array}{l}\text { HA } \\
\text { n }(\%)\end{array}$ & $\begin{array}{l}\mathrm{HB} \\
\mathrm{n}(\%)\end{array}$ & $\begin{array}{l}\mathrm{HA} \\
\mathrm{n}(\%)\end{array}$ & $\begin{array}{l}\text { HB } \\
\text { n (\%) }\end{array}$ \\
\hline Aspergillus $\mathrm{sp}$ & $2(20)$ & $6(30)$ & $5(50)$ & $6(30)$ & $1(10)$ & $2(10)$ & $2(20)$ & $6(30)$ & $10(24)$ & $20(25)$ \\
\hline $\begin{array}{l}\text { Aspergillus } \\
\text { niger }\end{array}$ & 0 & $4(27)$ & 0 & $3(20)$ & $\begin{array}{l}3 \\
(100)\end{array}$ & $4(27)$ & 0 & $4(27)$ & $3(7)$ & $\begin{array}{l}15 \\
(18)\end{array}$ \\
\hline Mucor spp. & $1(20)$ & $2(22)$ & $2(40)$ & $5(55)$ & $1(20)$ & $2(22)$ & $1(20)$ & 0 & $5(12)$ & $9(11)$ \\
\hline Rhizopus spp & $1(33)$ & $5(55)$ & $2(67)$ & $2(22)$ & 0 & $1(11)$ & 0 & $1(11)$ & $3(7)$ & $9(11)$ \\
\hline $\begin{array}{l}\text { Penicillium } \\
\text { spp. }\end{array}$ & 0 & $2(25)$ & 0 & $1(12)$ & 0 & $3(37)$ & $\begin{array}{l}2 \\
(100)\end{array}$ & $2(25)$ & $2(5)$ & $8(10)$ \\
\hline $\begin{array}{l}\text { Alternaria } \\
\text { spp. }\end{array}$ & $1(33)$ & 0 & $1(33)$ & $1(25)$ & 0 & 0 & $1(33)$ & $3(75)$ & $3(7)$ & $4(5)$ \\
\hline Epicoccum & $4(100)$ & $1(33)$ & 0 & $1(33)$ & 0 & 0 & 0 & $1(33)$ & $4(10)$ & $3(4)$ \\
\hline Fusarium spp & $3(60)$ & $1(50)$ & $1(20)$ & 0 & 0 & 0 & $1(20)$ & $1(50)$ & $5(12)$ & $2(2)$ \\
\hline Yeasts & 0 & 0 & 0 & 0 & 0 & $3(100)$ & $1(100)$ & 0 & $1(2)$ & $3(4)$ \\
\hline Scopulariopsis & 0 & 0 & 0 & 0 & 0 & 0 & $1(100)$ & 0 & $1(2)$ & 0 \\
\hline $\begin{array}{l}\text { Drechslera } \\
\text { spp. }\end{array}$ & 0 & $1(50)$ & 0 & 0 & 0 & 0 & $\begin{array}{l}1 \\
(100)\end{array}$ & $1(50)$ & $1(2)$ & $2(2)$ \\
\hline Psylomyces & $1(100)$ & 0 & 0 & $1(50)$ & 0 & 0 & 0 & $1(50)$ & $1(2)$ & $2(2)$ \\
\hline Phoma & 0 & 0 & 0 & 0 & 0 & 0 & $1(100)$ & 0 & $1(2)$ & 0 \\
\hline Ascocarpe & $1(100)$ & 0 & 0 & 0 & 0 & 0 & 0 & 0 & $1(2)$ & 0 \\
\hline $\begin{array}{l}\text { Mycelia } \\
\text { Sterilia }\end{array}$ & 0 & $1(33)$ & 0 & 0 & 0 & $1(33)$ & 0 & $1(33)$ & 0 & $3(4)$ \\
\hline Absidia & 0 & 0 & 0 & 0 & 0 & 0 & 0 & $1(100)$ & 0 & $1(1)$ \\
\hline
\end{tabular}

HA: Shariati Hospital; HB: Shahid Mohammadi Hospital 
The genus Aspergilus was the most frequent, occurring in 30 samples (24.59\%), and it was followed by Aspergilus niger (14.75\%), Mucor spp. (11.47\%), and Rhizopus spp. (9.83\%). Except for Fusarium spp. $(\mathrm{p}=0.008)$, there were no significant differences between the frequencies of fungi isolated in the samples from the two hospitals ( $\mathrm{p}>0.05)$. The incidence and seasonal variations of the fungi isolated from the soil of the two hospitals are as follows. The highest rate of fungal isolation $(30.33 \%)$ in both hospitals was in the winter, it was greater at Shariati Hospital than at Shahid Mohammadi Hospital (34.14\% versus 28.40\%). The minimum isolation occurred in the summer (17.2\%), with Shariati Hospital (12.20\%) being less than Shahid Mohammadi Hospital (19.75\%). Tables 2 indicates the seasonal variations of the different types of fungi isolated in the two hospitals. Aspergillus was the dominant fungus in both hospitals during the year. At Shariati Hospital, 100\% of the Aspergiluss niger species were isolated in the summer. In the spring, Mocur was dominant in both hospitals, and, in the winter, Rhizopus spp. was the dominant fungus at Shahid Mohammadi Hospital (55.5\%). This fungus was dominant in the spring at Shariati Hospital (66.7\%). At Shariati Hospital, Scopulariopsis, Drechslera, Penicillium spp., and Yeasts were only observed in the fall. However, yeast

\section{Discussion}

In this study, we described the seasonal variations of the fungi that were isolated from a large number of soil samples collected from Shahid Mohammadi Hospital and Shariati Hospital in Bandar Abbas, Iran. We compared the fungal distribution in the two hospitals while one of them was undergoing construction activities and the other was not. However, contrary to our expectations, there were no significant differences between the fungi populations at the two hospitals with the exception of Fusarium spp., which occurred in larger concentrations at the hospital where there was no construction activities taking place. Although the main objective of this study was investigate the presence of pathogenic fungi in the soils of the hospitals, the most common fungi were saprophytic soil-related fungi. Many studies in Iran have shown the presence of fungi in the air $(14,15)$. Although, many reports from around the word have shown that soils are important sources of fungi in hospitals $(5,8,13,16-18)$, there is little information about fungal flora in the soil in Iran. In the soil of Qazvin, the most fungi were isolated from the genus Cladosporium spp. (29.69\%) with Aspergillus spp. at 22.52\%. The high incidence of Cladosporium isolates was in contrast to our findings in which no Cladosporium spp. was isolated. However, the prevalence of Aspergillus spp. identified in our study was close to the value reported for the soil in Qazvin.

Penicillium spp. has been reported as the third most predominant soil-borne fungus (with a prevalence of $19.90 \%$ ) in Qazvin (13), and it was 52\% of the fungi isolated from soil samples from hospitals in Sari, Iran (15). Our results were in contrast with the reported values in that we found that Penicillium spp. accounted for $8.19 \%$ and was ranked fifth among the fungi recovered from soil samples. Another study in Sari in 2001 showed that the most common keratinophilic fungi isolated from forest soil were Chrysosporium and Microsporum gypseum and the most geophilic dermatophytes were Trichophyton terrestreand Trichophyton aioli (19). Among the potential pathogens that were identified, Mucor spp. and Rhizopus were the two most rapid growing fungi, so that the frequencies of Mucor spp. and Rhizopus in soil of two hospitals were respectively $11.47 \%$ and $9.83 \%$, and these fungi can cause infections in immunosuppressed, malnourished, or severely-burned people (13). We did not find the Chrysosporium species as was the case in other studies in Iran conducted by Hedayati et al., Moallaei et al., Shadzi et al. and Mahmoudabadi $(14,15,20,21)$. These studies reported that the incidence of this keratinophilic fungus was $3.7 \%, 8.40 \%, 41.6 \%$ and $54.2 \%$, respectively. The explanation for this may be the different climate of Bandar Abbas. Although the presence of allergenic and pathogenic fungi in the soil does not necessarily mean that they are causing problems for patients, but their presence does indicate that they present potential risk factors for particularly sensitive patients. In addition, the results of our study led to a better understanding of the pattern of soil-borne fungi, and this information may be helpful for physicians, allergists, and epidemiologists. A study of the seasonal distribution of fungi within a hospital located in Bandar Abbas showed that the outdoor fungal load was far higher in the winter. This result was inconsistent with the result of a French study that indicated that the fungal load was higher in the fall (22). Bandar Abbas is hot and humid, and the maximum temperature in the summer can reach $49{ }^{\circ} \mathrm{C}\left(120{ }^{\circ} \mathrm{F}\right)$; the minimum temperature in the winter usually is in the range to 8 to $10{ }^{\circ} \mathrm{C}\left(41-43{ }^{\circ} \mathrm{F}\right)$ with a mean relative humidity of $65 \%$. These climatic characteristics provide a suitable condition for fungal growth in the winter. This study is unique because there was no information on the background levels of fungal concentrations in outside soil samples during the period of construction at Shahid Mohammadi Hospital. Culture-based methods have some limitations in detecting some fungal genera, and Polymerase Chain Reaction is recommended to overcome these limitations. 


\section{Conclusions}

The results of this study indicated that there is a higher fungal load in winter and that there were no significant differences between the two hospitals with respect to the presence of fungi, with the exception of Fusarium spp. that was more abundant at Shariati Hospital where no construction was taking place. Our results indicated the presence of specific ecological niches in the two general hospitals in Bandar Abbas. That was due to ability that fungi have to grow in conditions of environmental stress, such as direct sunlight, high temperatures, low levels of moisture, and a range of $\mathrm{pH}$ values in the soil, which could allow them to be associated with soil-related, opportunistic infections. Since, a variety of soil-related bacterial and fungal pathogens can cause serious diseases in people, it is recommended that soil exposure be routinely considered in patient histories, along with food- and water-born infections, when infectious diseases are included in the diagnosis.

\section{Acknowledgments:}

This study was extracted from a research project conducted at the Hormozgan University of Medical Sciences. We thank the Vice Chancellor for Research at Hormozgan University of Medical Sciences, Student Research Committee, for the financial resources and equipment that were provided (grant number: 9301). We also thank Dr. Amir Seid Ali Mahbod for scientific counseling and Mr. Madjid Najafi for his technical assistance in this project.

\section{Conflict of Interest:}

There is no conflict of interest to be declared.

Authors' contributions:

All authors contributed to this project and article equally. All authors read and approved the final manuscript.

\section{References}

1) Vincent JL, Rello J, Marshall J, Silva E, Anzueto A, Martin CD, et al. International study of the prevalence and outcomes of infection in intensive care units. Jama. 2009; 302 (21): 2323-9. doi: 10. 1001/jam.2009.1754. PMID: 19952319

2) Badiee P, Alborzi A, Joukar M. Molecular assay to detect nosocomial fungal infections in intensive care units. Eur J Intern Med. 2011; 22 (6): 611-5. doi: 10.1016/j.ejim.2011.08.025. PMID: 22075290

3) Kanamori H1, Rutala WA, Sickbert-Bennett EE, Weber DJ. Review of Fungal Outbreaks and Infection Prevention in Healthcare Settings During Construction and Renovation. Clin Infect Dis. 2015; 61 (3): 433 44. doi: 10.1093/cid/civ297. PMID: 25870328

4) Shor E, Perlin DS. Coping with stress and the emergence of multidrug resistance in fungi. PLoS pathog. 2015; 11 (3): e1004668. doi: 10.1371/journal.ppat.1004668. PMID: 25790300, PMCID: PMC4366371

5) Faure O, Fricker-Hidalgo H, Lebeau B, Mallaret MR, Ambroise-Thomas P, Grillot R. Eight-year surveillance of environmental fungal contamination in hospital operating rooms and haematological units. J Hosp Infect. 2002; 50 (2): 155-60. doi: 10.1053/jhin.2001.1148. PMID: 11846544

6) Le T, Wolbers M, Chi NH, Quang VM, Chinh NT, Lan NP, et al. Epidemiology, seasonality, and predictors of outcome of AIDS-associated Penicillium marneffei infection in Ho Chi Minh City, Viet Nam. Clin Infect Dis. 2011; 52 (7): 945-52. doi: 10.1093/cid/cir028. PMID: 21427403, PMCID: PMC3106230

7) Baumgardner DJ. Soil-related bacterial and fungal infections. JABFM. 2012; 25 (5): 734-44. doi: 10.3122/jabfm.2012.05.110226

8) Perdelli F, Cristina ML, Sartini M, Spagnolo AM, Dallera M, Ottria G, et al. Fungal contamination in hospital environments. Infect Control Hosp Epidemiol. 2006; 27 (1): 44-7. PMID: 16418986

9) Menzin J, Meyers JL, Friedman M, Korn JR, Perfect JR, Langston AA, et al. The economic costs to United States hospitals of invasive fungal infections in transplant patients. Am J Infect control. 2011; 39 (4): e1520. doi: 10.1016/j.ajic.2010.06.009. PMID: 20961657

10) Drgona L, Khachatryan A, Stephens J, Charbonneau C, Kantecki M, Haider S, et al. Clinical and economic burden of invasive fungal diseases in Europe: focus on pre-emptive and empirical treatment of Aspergillus and Candida species. Eur J Clin Microbiol infect Dis. 2014; 33 (1): 7-21. doi: 10.1007/s10096-013-1944-3. PMCID: PMC3892112

11) Statistical center of Iran, Management \& planning organization. Bandar Abbas statistics. Available from https://www.amar.org.ir/Default.aspx?tabid=667\&fid=14095

12) Singh I, Mishra A, Kushwaha R. Dermatophytes, related keratinophilic and opportunistic fungi in indoor dust of houses and hospitals. Indian J Med Microbiol. 2009; 27 (3): 242-6. DOI: 10.4103/0255-0857.53207 
13) Aghamirian MR, Ghiasian SA. ThePrevalence of Fungi in Soil of Qazvin, Iran. Jundishapur J Microbiol. 2013; 6 (1): 76-79. doi: 105812/jjm4591.

14) Hedayati MT, Mayahi S, Aghili R, Goharimoghadam K. Airborne fungi in indoor and outdoor of asthmatic patients' home, living in the city of sari. Iran J Allergy Asthma Immunol. 2005; 4 (4): 189-91. PMID: 17301445

15) Hedayati MT, Mohseni-Bandpi A, Moradi S. A survey on the pathogenic fungi in soil samples of potted plants from Sari hospitals. Iran J Hosp Infect. 2004; 58 (1): 59-62. PMID: 15350715

16) Rainer J, Peintner U, Pöder R. Biodiversity and concentration of airborne fungi in a hospital environment. Mycopathologia. 2000; 149 (2): 87-97. doi: 10.1023/A:1007273131130

17) Shadzi S, Zahraee MH, ChadeganiPour M. Incidence of airborne fungi in Isfahan, Iran. Mycoses. $1993 ; 36$ (1-2): 69-73. doi: 10.1111/j.1439-0507.1993.tb00689.x. PMID: 8316264

18) Arvanitidou M, Kanellou K, Constantinides TC, Katsouyannopoulos V. The occurrence of fungi in hospital and community potable waters. Lett appl microbiol. 1999; 29 (2): 81-4. doi: 10.1046/j.13652672.1999.00583.x. PMID: 10499294

19) Shokoohi T, Bakhshi H, Hedayati MT. Distribution of fungi and Actinomycetes in the soil of different regions of Sari and its suburbs. J Kermanshah Univ Med Sci. 2005; 8 (23): 57-69.

20) Moallaei H, Zaini F, Pihet M, Mahmoudi M, Hashemi J. Isolation of Keratinophilic Fungi from Soil Samples of Forests and Farm Yards . Iranian J Publ Health 2006; 35(4): 62-69.

21) Zarei Mahmoudabadi A, Zarrin M. Isolation of dermatophytes and related keratinophilic fungi from the two public parks in Ahvaz. Jundishapur J Microbiol. 2008; 1(1): 20-3.

22) Sautour M, Sixt N, Dalle F, L'Ollivier C, Fourquenet V, Calinon C, et al. Profiles and seasonal distribution of airborne fungi in indoor and outdoor environments at a French hospital. Sci Total Environ. 2009; 407(12): 3766-71. doi: 10.1016/j.scitotenv.2009.02.024. PMID: 19286244 